\title{
Lightning may pose a danger to patients receiving deep brain stimulation: case report
}

\author{
Neža Prezelj, MD, ${ }^{1}$ Maja Trošt, MD, PhD,,2 Dejan Georgiev, MD, PhD, ${ }^{1}$ and Dušan Flisar, MD1 \\ 'Department of Neurology, University Medical Centre Ljubljana; and ${ }^{2}$ Faculty of Medicine, University of Ljubljana, Slovenia
}

Deep brain stimulation (DBS) is an established treatment option for advanced stages of Parkinson's disease and other movement disorders. It is known that DBS is susceptible to strong electromagnetic fields (EMFs) that can be generated by various electrical devices at work, home, and in medical environments. EMFs can interfere with the proper functioning of implantable pulse generators (IPGs). Very strong EMFs can generate induction currents in implanted electrodes and even damage the brain. Manufacturers of DBS devices have issued a list of warnings on how to avoid this danger.

Strong EMFs can result from natural forces as well. The authors present the case of a 66-year-old woman who was being treated with a rechargeable DBS system for neck dystonia when her apartment was struck by lightning. Domestic electronic devices that were operating during the event were burned and destroyed. The woman's IPG switched off but remained undamaged, and she suffered no neurological consequences.

https://thejns.org/doi/abs/10.3171/2017.12.JNS172258

KEYWORDS deep brain stimulation; electromagnetic interference; lightning; functional neurosurgery

$\mathrm{D}$ EEP brain stimulation (DBS) is increasingly used to treat medically refractory movement disorders including Parkinson's disease, essential tremor, and dystonia. ${ }^{5,11,12}$ Neurostimulators are implanted for this treatment; however, there are a number of electrical devices in the environment that may affect the function of these devices. The proper functioning of implantable pulse generators (IPGs) can be impaired by electromagnetic interference emanating from electronic devices, electrical machinery, or metal detectors. Strong electromagnetic fields (EMFs) can generate induction currents in implanted electrodes and even damage the brain. ${ }^{1,2}$ In addition, naturally generated EMFs in the environment can also pose a threat to patients receiving DBS. We report a case in which a nearby lightning strike caused inadvertent deactivation of a patient's IPG. To the best of our knowledge, this is the first report of such an event.

\section{Case Report}

A 66-year-old woman was treated with bilateral globus pallidus internus DBS (Activa RC neurostimulator,
Medtronic) for neck dystonia over a period of 5 years with a very good clinical response. The electrical installation of her apartment was struck by lightning during a thunderstorm. Electrical devices (a television and air conditioner) operating in the apartment at that time were burned and destroyed. The patient was not charging the battery of her IPG during the event, and the recharger for the IPG was disconnected from the power supply during the storm. The recharger and IPG were therefore not destroyed. The patient realized that something was wrong only 1 hour after the storm subsided, when the dystonic tremor in her neck reappeared. When she checked the function of her IPG, the POR (Power On Reset) warning appeared on her patient programmer's display. The patient was afraid that her IPG was damaged and came to the outpatient clinic for assistance.

Examination of the device showed that stimulation was turned off, but all other stimulation parameters remained unchanged. The battery was still $50 \%$ charged, which agreed with the patient's earlier use and meant that the lightning had not decreased the battery storage. The whole 
DBS system remained undamaged, and the patient suffered no other neurological consequences. After switching the stimulator on, the patient's dystonic tremor resolved almost immediately and her neck dystonia improved.

\section{Discussion}

Proximity to high levels of electromagnetic interference may cause DBS system damage, unexpected changes in neurostimulator function, and even serious injury to the patient. ${ }^{1,2,6}$ The manufacturers of DBS devices (Medtronic, Abbott/St. Jude Medical, and Boston Scientific) issued a list of warnings on how to avoid this danger. (For additional information regarding the list of warnings, please see industry guidelines of the manufacturers.) Of note, the Medtronic, Boston Scientific and Abbott/St. Jude Medical DBS rechargeable devices are now approved for use in the United States by the Federal Drug Administration.

Patients should be regularly warned to avoid environmental sources that generate strong EMFs, such as arc welding equipment, electronic power generators, electrical substations, ham radio antennas, power lines, microwave communication transmitters, industrial furnaces, induction heaters, resistance welders, and transmission towers for television and radio signals. There have been some studies and a few case reports about the safety of and compatibility between DBS systems and medical devices that generate strong EMFs, such as MRI units, cardioverter machines, and diathermy devices, which potentially may be harmful to patients and their IPGs., ${ }^{1,6,10}$ The issue of compatibility between MRI and DBS has been discussed in a number of reports in the literature, and there are a few case reports about adverse effects and serious brain injury following MRI examinations in patients with neurostimulators due to failure to strictly follow safety recommendations. ${ }^{4,9}$

The rechargeable DBS system is composed of 3 electronic components: the AC power supply, the recharger with an antenna, and the IPG. In the case of the Medtronic Activa RC, it is possible to charge the recharger and the battery of the stimulator at the same time. In this way, a continuous charging chain can be established. This action could be potentially dangerous for the patient should he or she try to charge the recharger and IPG battery simultaneously during a thunderstorm. Luckily, our patient was not charging her IPG or the recharger during the storm, and she did not have the recharger plugged into the AC power supply at that time. Hence there was no damage to the electronic components of the IPG or any other serious consequences for the patient.

The Medtronic device has an integrated safety system that detects errors such as the ones caused by electromagnetic interference. This occurred in our patient and the IPG automatically switched off. This event suggests that the Medtronic Activa RC is protected from damage after exposure to strong EMFs - even after exposure to nearby lightning. However, inadvertent interruption of DBS in patients treated for dystonia could trigger a dystonic storm if the stimulation is not reestablished in time. $3,7,8$

Patients treated with DBS must always be instructed to immediately check the functioning of their IPGs if they detect deterioration in their symptoms, especially after encountering a strong external EMF. We also recommend that the IPG charger be plugged into a surge protector, which is an inexpensive electronic device, especially if there is a concern for high-voltage spikes. In addition, many modern buildings have whole-house surge protection, which might additionally help prevent significant voltage changes. If not, a surge protector installed directly between the electrical outlet and the electronic device could prevent damage to the device in such a situation. As a further precaution for patients with a Medtronic Activa RC, it is reasonable to recommend that the recharger be charged first and disconnected from the electrical outlet before being used to charge the IPG. We also advise all clinicians to regularly warn DBS patients to strictly follow the manufacturer's safety recommendations and not to charge the recharger and IPG simultaneously during a thunderstorm. Last, we propose that in the future DBS manufacturers' safety recommendations should specifically mention the possibility of hazards from naturally generated electromagnetic interference, such as during thunderstorms.

\section{References}

1. Blomstedt P, Jabre M, Bejjani BP, Koskinen LO: Electromagnetic environmental influences on implanted deep brain stimulators. Neuromodulation 9:262-269, 2006

2. Dustin K: Evaluation of electromagnetic incompatibility concerns for deep brain stimulators. J Neurosci Nurs 40:299303, 319, 2008

3 . Frucht SJ: Treatment of movement disorder emergencies. Neurotherapeutics 11:208-212, 2014

4. Henderson JM, Tkach J, Phillips M, Baker K, Shellock FG, Rezai AR: Permanent neurological deficit related to magnetic resonance imaging in a patient with implanted deep brain stimulation electrodes for Parkinson's disease: case report. Neurosurgery 57:E1063, 2005

5. Kumar R, Lozano AM, Sime E, Lang AE: Long-term followup of thalamic deep brain stimulation for essential and parkinsonian tremor. Neurology 61:1601-1604, 2003

6. Rezai AR, Phillips M, Baker KB, Sharan AD, Nyenhuis J, Tkach J, et al: Neurostimulation system used for deep brain stimulation (DBS): MR safety issues and implications of failing to follow safety recommendations. Invest Radiol 39:300-303, 2004

7. Rohani M, Munhoz RP, Shahidi G, Parvaresh M, Miri S: Fatal status dystonicus in tardive dystonia due to depletion of deep brain stimulation's pulse generator. Brain Stimul 10:160-161, 2017 (Letter)

8. Sobstyl M, Ząbek M, Kmieć T, Sławek J, Budohoski KP: Status dystonicus due to internal pulse generator depletion in a patient with primary generalized dystonia. Mov Disord 29:188-189, 2014

9. Spiegel J, Fuss G, Backens M, Reith W, Magnus T, Becker G, et al: Transient dystonia following magnetic resonance imaging in a patient with deep brain stimulation electrodes for the treatment of Parkinson disease. Case report. J Neurosurg 99:772-774, 2003

10. Tagliati M, Jankovic J, Pagan F, Susatia F, Isaias IU, Okun MS: Safety of MRI in patients with implanted deep brain stimulation devices. Neuroimage 47 (Suppl 2):T53-T57, 2009

11. Vidailhet M, Vercueil L, Houeto JL, Krystkowiak P, Benabid AL, Cornu P, et al: Bilateral deep-brain stimulation of the globus pallidus in primary generalized dystonia. N Engl J Med 352:459-467, 2005 
12. Weaver FM, Follett KA, Stern M, Luo P, Harris CL, Hur $\mathrm{K}$, et al: Randomized trial of deep brain stimulation for Parkinson disease: thirty-six-month outcomes. Neurology 79:55-65, 2012

\section{Disclosures}

The authors report no conflict of interest concerning the materials or methods used in this study or the findings specified in this paper.

\section{Author Contributions}

Conception and design: Flisar, Prezelj. Drafting the article: Prezelj. Critically revising the article: Flisar, Trošt, Georgiev. Reviewed submitted version of manuscript: Flisar, Trošt, Georgiev. Approved the final version of the manuscript on behalf of all authors: Flisar.

\section{Correspondence}

Dušan Flisar: University Medical Centre Ljubljana, Slovenia. dusan.flisar@kclj.si. 